\title{
Transmembrane Sema4E Guides Branchiomotor Axons to Their Targets in Zebrafish
}

\author{
Tong Xiao, ${ }^{1}$ Wataru Shoji, ${ }^{2}$ Weibin Zhou, ${ }^{1}$ Fengyun Su, ${ }^{1}$ and John Y. Kuwada ${ }^{1}$

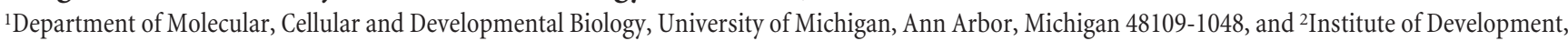 \\ Aging, and Cancer, Tohoku University, Sendai 980-8575, Japan
}

\begin{abstract}
Class 4 semaphorins are a large class of transmembrane proteins that contain a sema domain and that are expressed in the CNS, but their in vivo neural function is unknown. In zebrafish, the epithelial cells that line the pharyngeal arches express Sema4E. Extension of branchiomotor axons along the mesenchymal cells bounded by these epithelial cells suggests that Sema4E may act as a repulsive guidance molecule to restrict the branchiomotor axons to the mesenchymal cells. To test this hypothesis, Sema4E was misexpressed in $h s p 70$ promoter-regulated transgenic zebrafish in which sema4E was heat-inducible, and Sema4E was knocked down by injection of antisense morpholino oligonucleotides that acted specifically against Sema4E. Ubiquitous induction of Sema4E retarded outgrowth by the facial and gill branchiomotor axons significantly. Furthermore, outgrowth by gill motor axons was specifically inhibited when Sema4Eexpressing transgenic cells were transplanted to their pathway in nontransgenic host embryos. Morpholino knockdown of Sema4E caused facial motor axons to defasciculate and follow aberrant pathways. These results show that Sema4E is repulsive for facial and gill motor axons and functions as a barrier for these axons within the pharyngeal arches.
\end{abstract}

Key words: axon guidance; zebrafish; semaphorin; motor axon; transgenic; morpholino knockdown

\section{Introduction}

The semaphorin family of proteins is a large family of secreted and cell surface molecules, several members of which are known to repel or attract specific growth cones (Raper, 2000). These proteins have a characteristic extracellular sema domain of $\sim 500$ amino acids and are grouped into subclasses based on other structural domains. There are eight subfamilies of semaphorins: two invertebrate classes, five vertebrate classes, and one viral class (Semaphorin Nomenclature Committee, 1999). The two largest subfamilies are the vertebrate class 3 secreted semaphorins (Sema3) and the vertebrate class 4 transmembrane semaphorins (Sema4).

The most extensively studied semaphorins are the class 3 semaphorins, and within this class, the most extensively studied is Sema3A. Sema3A, previously known as collapsin-1, was the first semaphorin shown to be repulsive for growth cones (Luo et al., 1993). In vitro, Sema3A repulsed or collapsed growth cones from a variety of neurons in both the CNS and PNS (Raper, 2000). In Sema3A-deficient mice, a subset of cranial nerves was defasciculated abnormally; peripheral nerves projected incorrectly in the eye and limb; and the sympathetic chain ganglia were aberrant (Taniguchi et al., 1997).

Despite the fact that the Sema4 proteins represent one of the largest classes of semaphorins (seven members to date), the function of only one member, Sema 4 D/CD100, is well characterized.

\footnotetext{
Received Sept. 4, 2002; revised Dec. 24, 2002; accepted Jan. 17, 2003.

This study was supported by Grant NS36587 from the National Institute of Neurological Disorders and Stroke to J.Y.K. We thank Dr. Hitoshi Okamoto for providing the is/1: gfp transgenic fish, Dr. Marc Ekker for the $d / x 3$ CDNA, and Drs. Pamela Raymond and Kate Barald for helpful discussions.

Correspondence should be addressed to Dr. John Y. Kuwada, Department of Molecular, Cellular and Developmental Biology, University of Michigan, Ann Arbor, Ml 48109-1048. E-mail: kuwada@umich.edu.

Dr. Xiao's present address: Department of Physiology, University of California, San Francisco, CA 94143-0444. Copyright $\odot 2003$ Society for Neuroscience $\quad$ 0270-6474/03/234190-09\$15.00/0
}

Sema4D/CD100 has a critical role in the immune system. It is expressed by lymphocytes (Delaire et al., 1998), promotes the aggregation and survival of B lymphocytes in vitro (Hall et al., 1996), and inhibits cytokine-induced migration of immune cells in vitro (Delaire et al., 2001). Sema4D/CD100 knock-out mice demonstrated that it is required for normal activation of $\mathrm{B}$ and $\mathrm{T}$ lymphocytes (Shi et al., 2000). Sema4D/CD100 is also abundantly expressed in the nervous system (Furuyama et al., 1996), but macroscopic anatomical and histological analyses and behavioral analyses revealed no apparent nervous system abnormalities in the knock-out mice (Shi et al., 2000). Two other class 4 semaphorins, Sema4F and Sema4C, collapse retinal axons in vitro (Encinas et al., 1999) and interact with a postsynaptic density protein (Inagaki et al., 2001), respectively, which indicates that class 4 semaphorins may play a role in nervous system function in vivo. Several other transmembrane semaphorins from other classes of semaphorins are also known to affect growth cones. For example, the insect class 1 semaphorin, Sema-1a, guides sensory growth cones in the grasshopper limb bud via an attractive action (Kolodkin et al., 1992; Wong et al., 1997, 1999), and the vertebrate class 6 semaphorin, Sema6A, can collapse growth cones of sympathetic neurons in vitro (Xu et al., 2000).

To better investigate the nervous system function of class 4 semaphorins, we identified zebrafish Sema4E (previously known as SemaZ7; Halloran et al., 1998), a novel semaphorin that has no known orthologs identified in other species. At $24 \mathrm{hr}$ postfertilization (HPF), which is the stage of early axonogenesis in the zebrafish, sema4E is expressed in the dorsal hindbrain, in dorsal and ventral stripes of cells in spinal cord, in the dorsal tectum, and in the pharyngeal arches. To study the in vivo function of Sema4E, we used injections of antisense morpholino oligonucleotides (MOs) (Heasman et al., 2000; Nasevicius and Ekker, 2000) and generated heat-inducible $h s p 70: s e m a 4 E$ transgenic zebrafish 
(Halloran et al., 2000) to manipulate sema4E expression. Here we show that Sema4E is both necessary and sufficient for the guidance of facial axons from the hindbrain into their pharyngeal arch targets and sufficient for guidance of gill motor axons.

\section{Materials and Methods}

Fish breeding and maintenance. Zebrafish were maintained at $28.5^{\circ} \mathrm{C}$ on a $14 / 10 \mathrm{hr}$ light/dark cycle in a recirculating water breeding facility. Embryos were collected after natural spawns, developed at $28.5^{\circ} \mathrm{C}$, and staged by HPF as described previously (Kimmel et al., 1995). Wild-type, isl1:gfp (Higashijima et al., 2000), hsp70: ${ }^{8 f P}$ sema3A1 ${ }^{m y c}$ (Halloran et al., 2000), and $h s p 70: s e m a 4 E^{g f p}$ zebrafish were used for this study.

Generation of expression construct. Construct $p H s p 70 / 4: s e m a 4 E^{g f p}$ was made by insertion of a $3 \mathrm{~kb}$ sema4E full-length cDNA into the pHsp70/4:gfp vector (Halloran et al., 2000) between the SalI and NotI restriction sites. The sema4E stop codon was removed by PCR, and the egfp sequence was fused to the $\mathrm{C}$ terminus of sema4E. A fusion fragment of BsrGI and NotI sema4E $E^{g f p}$ was inserted into the $p H s p 70 /$ 4:sema $4 E$ vector to replace the $C$ terminus of sema $4 E$ to generate the $p H s p 70 / 4$ :sema4E $E^{g f p}$ expression construct. Portions of the insert were amplified by PCR and sequenced to rule out errors. Four primers were used for the PCR reaction: (1) 5'GATGATGAATCAGAGATTCCACCGGTCGCCACC-3'; (2) 5'-GGTGGCGACCGGTGGAATCTCTGATTCATCATC-3'; (3) 5'-AAAGCGGCCGCGACTCTAGATCATAATC-3'; and (4) $5^{\prime}$-CCTTTTACCACGGGATACC-3'.

Generation of transgenic fish and induction of sema4E. Plasmid DNA for injection was prepared with the Qiagen (Hilden, Germany) Maxi Kit and diluted to $50 \mu \mathrm{g} / \mathrm{ml}$ in distilled water that contained $0.2 \%$ phenol red. Micropipettes for DNA injections were pulled from thin-walled, fiber-filled glass tubing ( $1 \mathrm{~mm}$ outer diameter) with a Sutter microelectrode puller and back filled by capillary action with DNA solution. Recently fertilized embryos (one- to four-cell stage) were put in an embryo injection chamber and mounted onto a compound microscope (Zeiss, Oberkochen, Germany). Micropipettes were inserted in a pressure injection microelectrode holder (WPI) that was mounted on a micromanipulator (Leitz, Wetzlar, Germany). The tips of the micropipettes were broken to $\sim 1 \mu \mathrm{m}$ in diameter before injections. Embryos were viewed at $50 \times$ magnification, and DNA $(50 \mu \mathrm{g} / \mathrm{ml})$ was injected by insertion of the micropipette tip into blastomeres from the vegetal poles. DNA was injected into embryos with several pressure pulses (10-20 psi, $100 \mathrm{msec}$ ) delivered by a Picospritzer (General Valve, Fairfield, NJ). The volume of the microinjected DNA as indicated by the phenol red was one-fifth of the volume of cytoplasm.

Injected embryos were raised to sexual maturity and crossed in a pair-wise manner to identify founder fish. PCR was used to identify founders. Genomic DNA was extracted from pools of 150-200 2- to 3 -d-old F1 embryos from the pair-wise crosses. Embryos were incubated overnight at $55^{\circ} \mathrm{C}$ in an equal volume of lysis buffer $(100 \mathrm{~mm}$ Tris- $\mathrm{HCl}, \mathrm{pH} 8.5,5 \mathrm{~mm}$ EDTA, 0.2\% SDS, $200 \mathrm{~mm} \mathrm{NaCl}$, and 100 $\mu \mathrm{g} / \mathrm{ml}$ proteinase $\mathrm{K})$. After digestion, samples were extracted with chloroform and precipitated with isopropanol, and the DNA was washed in $70 \%$ ethanol and dissolved in distilled water overnight for use as a template in PCR reactions. PCR reactions were performed with primers (5' -CGTCCATGCCGAGAGTGATC- $3^{\prime}$ and $5^{\prime}$-TCAAGTCCGCCATGCCCGAA-3') from the enhanced green fluorescent protein (EGFP) sequence to yield a 452 bp product. PCR reactions were performed on $\sim 100-200 \mathrm{ng}$ of DNA in $1 \times$ PCR buffer (Promega, Madison, WI) with $2 \mathrm{mM} \mathrm{MgCl}_{2}$, an $8 \mathrm{ng} / \mu$ l concentration of each primer, and $0.2 \mathrm{~mm}$ deoxynucleoside $5^{\prime}$-triphosphates. PCR reactions consisted of an initial denaturation step of $5 \mathrm{~min}$ and 30 cycles of $1 \mathrm{~min}$ at $94^{\circ} \mathrm{C}, 45 \mathrm{sec}$ at $58^{\circ} \mathrm{C}$, and $1 \mathrm{~min} 30 \mathrm{sec}$ at $72^{\circ} \mathrm{C}$.

After a pair had been identified, the male and female were crossed with wild-type fish to identify the founder fish. The F1 embryos from the founder were heat-induced by elevation of their temperature to $37^{\circ} \mathrm{C}$ for $1 \mathrm{hr}$ and assayed for GFP expression by examination on a compound microscope. In the present experiments, sema $4 E^{g f p}$ was induced in transgenic embryos by the same procedure. In all $h s p 70: s e m a 4 E^{g f p}$ misexpression experiments, homozygous embryos were used.
Sema4E ${ }^{\text {GFP }}$ from heat-induced $h s p 70: s e m a 4 E^{g f p}$ transgenic embryos was detected by Western blotting. The chorion and yolk were removed from embryos, and the proteins were extracted by lysing the embryos with lysis buffer (0.5\% NP-40, 0.1\% BSA, 5 mм EDTA, 1 mм PMSF, 10 $\mu \mathrm{g} / \mathrm{ml}$ leupeptin, and $10 \mu \mathrm{g} / \mathrm{ml}$ aprotinin in $1 \times \mathrm{TBS})$. Proteins were separated in a 7.5\% SDS-PAGE gel in Tris-glycine electrophoresis buffer (25 mM Tris and $250 \mathrm{~mm}$ glycine, $\mathrm{pH} 8.3$ ) and then transferred to nitrocellulose membrane (Millipore, Bedford, MA). The membrane was blocked in blocking buffer ( $2 \%$ nonfat dry milk, $1 \%$ BSA, and $0.05 \%$ Tween 20 in PBS) overnight and probed with a rabbit polyclonal antiGFP antibody (Chemokine) at 1:25,000 dilution. Horseradish peroxidase-coupled anti-rabbit IgG (Sigma, St. Louis, MO) was used as a secondary antibody. Chemiluminescence (ECL detection system; Amersham Biosciences, Arlington Heights, IL) was used to detect the immunoreactivity signal.

In situ hybridization and immunocytochemistry. Sense and antisense riboprobes for sema $4 E$, $\operatorname{tag}-1$, and $d l x$-3 labeled with digoxigenin-labeled UTP were generated by in vitro transcription from their cDNA clones. The probes were hydrolyzed to 300 bases in $100 \mathrm{mM} \mathrm{Na}_{2} \mathrm{CO}_{3}$ and $\mathrm{NaHCO}_{3}, \mathrm{pH}$ 10.2. In situ hybridization to whole-mounted embryos was performed according to previously described protocols (Schulte-Merker et al., 1992). The whole-mount antibody labeling was performed as described previously (Westerfield, 1995). For immunocytochemistry, the following antibodies and concentrations were used: anti-GFP (Chemokine), 1:25,000; zn-5 antibody (Trevarrow et al., 1990; Antibody Facility, University of Oregon), 1:500; islet antibody (39.4D5; Korzh et al., 1993; Developmental Studies Hybridoma Bank, University of Iowa), 1:500; and anti-SV2 (Developmental Studies Hybridoma Bank), 1:100.

DiI labeling and photoconversion of branchiomotor axons. Embryos were fixed for $1 \mathrm{hr}$ at $4^{\circ} \mathrm{C}$ in $4 \%$ paraformaldehyde in $100 \mathrm{~mm} \mathrm{PO}_{4}$ buffer (PB). The embryos were washed four times in $\mathrm{PB}$ and embedded in $1 \%$ low-melting point agarose on a glass slide. The agarose overlying the hindbrain was removed to expose it, and the embedded embryos were submerged in PB. The slide was mounted on a microscope stage, and the branchiomotor neurons were labeled with the fluorescent lipophilic dye DiI (Molecular Probes, Eugene, OR) by pressure injection. The injected embryos were incubated at $4^{\circ} \mathrm{C}$ in a dark, humid chamber for $6-8 \mathrm{hr}$ to allow the DiI to label the branchiomotor axons anterogradely. The labeled embryos were freed from the agarose and refixed for $2 \mathrm{hr}$ in $4 \%$ paraformaldehyde in $100 \mathrm{~mm} \mathrm{~PB}$. The embryos were washed four times in $\mathrm{PB}$ and then incubated in $\mathrm{PB}$ containing $0.5 \mathrm{mg} / \mathrm{ml} \mathrm{DAB}$ for $15 \mathrm{~min}$ and mounted on a slide in a drop of DAB and PB onto a fluorescence microscope. The fluorescence in the labeled cells was used to photooxidize DAB into a brown reaction product. After photoconversion, the embryos were washed in $\mathrm{PB}$, fixed overnight in $4 \%$ paraformaldehyde, and then mounted in 70\% glycerol and PBS for viewing.

MO injection. MOs were obtained from Gene Tools, LLC. The antisense sema $4 E$ morpholino sequence ( 28 mer) was complementary to a sequence of $3 \mathrm{bp}$ of the $5^{\prime}$ untranslated region immediately upstream of the codon that encoded the start methionine and $25 \mathrm{bp}$ of the coding sequence. The control morpholino sequence had four bases mismatched compared with the sema4E antisense morpholino sequence. Sequences were as follows: sema4E antisense MO, 5' -ACAGAACAGCCAGCAGAGACATCATTCA-3'; and sema4E control MO, 5'-ACACAACTGCCAGCAGAGTCATGATTCA-3'. MOs were solubilized in $1 \times$ Danieau solution [58 mм NaCl, $0.7 \mathrm{~mm} \mathrm{KCl}, 0.4 \mathrm{~mm} \mathrm{MgSO}_{4}, 0.6 \mathrm{~mm} \mathrm{Ca}\left(\mathrm{NO}_{3}\right)_{2}$, and $5 \mathrm{~mm}$ HEPES, pH 7.6] and injected into one- to eight-cell-stage embryos. For testing knockdown efficiency of the MOs, $\sim 9 \mathrm{ng}$ of $\mathrm{MO}$ ( $3 \mathrm{nl}$ of a $3 \mu \mathrm{g} / \mu \mathrm{l}$ MO solution) was injected into hsp70:sema4E $E^{g f p}$ embryos; for other experiments, $\sim 3 \mathrm{ng}$ of $\mathrm{MO}(3 \mathrm{nl}$ of a $1 \mu \mathrm{g} / \mu \mathrm{l} \mathrm{MO}$ solution) was injected.

Generation of transgenic/wild-type mosaic embryos. Mosaic embryos were generated by transplantation (Ho and Kane, 1990) of transgenic cells into nontransgenic embryos. Four to five HPF hsp70:sema4E $E^{g f p}$ transgenic embryos were donors, and wild-type embryos were hosts. Because the cells from $h s p 70$ :sema $4 E^{g f p}$ transgenic embryos could be detected with anti-GFP antibody labeling, the donor embryos were not labeled. The micropipettes for transplantation were pulled with fiberfilled, thin-walled glass capillary tubing ( $1 \mathrm{~mm}$ outer diameter) with a 
Sutter microelectrode puller. The tips were broken to $30-40 \mu \mathrm{m}$ in diameter and then polished with a Microfuge. Touching the leading edge of the micropipette to the filament and quickly drawing it away produced a sharp tip that facilitated the penetration of the micropipette into the embryos. Embryos were mounted in 3\% methylcellulose. Approximately $30-100$ cells were injected into each host embryo near the margin area. After transplantation, the embryos were placed into regular fish system water. The mosaic embryos were heat-induced to express Sema ${ }^{\text {GFP }}$ at 28 and 35 HPF. The transgenic cells were detected by anti-GFP, and the branchiomotor axons were analyzed with anti-SV2 and anti-GFP at $48 \mathrm{HPF}$.

Labeling of blood vessels in the pharyngeal arches. Blood vessels in 48 HPF embryos were labeled by tetramethylrhodamine dextran $(10,000$ molecular weight, neutral; Molecular Probes) injection. Embryos were anesthetized with $0.02 \%$ Tricaine (Sigma) and embedded in $1 \%$ agarose. A solution of $5 \%$ tetramethylrhodamine dextran in $0.2 \mathrm{M} \mathrm{KCl}$ was injected into the cardinal vein of the tail. After they were labeled, embryos were rinsed with system water to allow the recovery of the blood circulation. Labeling was imaged with an epifluorescence compound microscope.

Whole-mount cartilage labeling. Head cartilage in 5-d-old larvae was labeled by alcian blue staining (Dingerkus and Uhler, 1977; Kelly and Bryden, 1983). Larvae were fixed in $4 \%$ paraformaldehyde in PBS overnight and then transferred to a $0.1 \%$ solution of alcian blue dissolved in $80 \%$ ethanol and $20 \%$ glacial acetic acid. After they were stained overnight, larvae were washed in ethanol and rehydrated gradually into PBS. Tissues were cleared with $0.05 \%$ trypsin dissolved in a saturated solution of sodium tetraborate for 1-3 hr. Pigmentation was removed by bleaching the larvae in $3 \%$ hydrogen peroxide and $1 \% \mathrm{KOH}$ for several hours. The stained preparation was mounted in $70 \%$ glycerol and PBS.

\section{Results}

\section{sema4E expression in the pharyngeal arches correlates with} the pathways followed by branchiomotor axons

sema4E is expressed in an interesting and dynamic pattern that suggests that it guides branchiomotor axons into their pharyngeal arch targets (Halloran et al., 1998). Axons of the nVII facial motor neurons extend into the hyoid arch; axons of the nIX gill

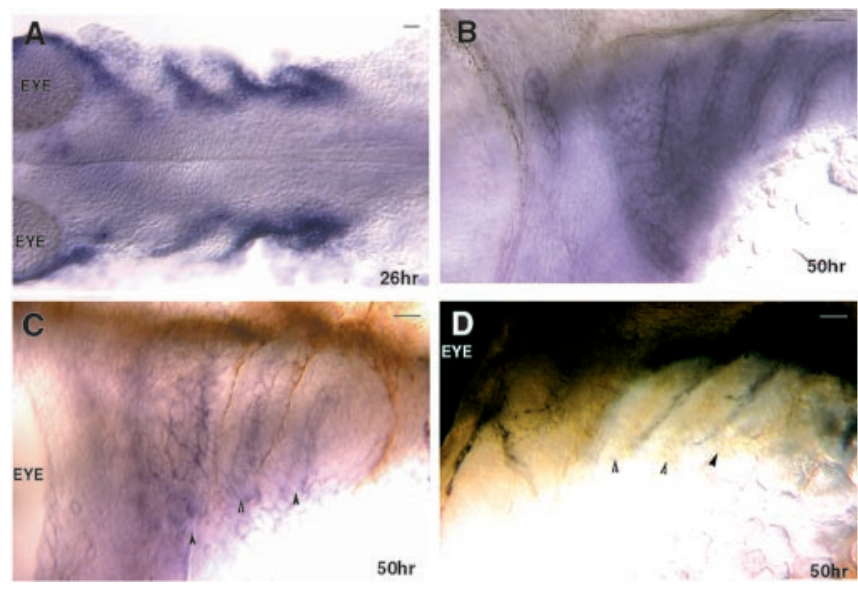

Figure 1. sema4E is expressed at the boundary of each pharyngeal arch. $A$, Dorsal view of an in situ hybridization of a $26 \mathrm{HPF}$ embryo showing that sema4E is expressed at the boundaries between pharyngeal arches. $B$, Lateral view of an in situ hybridization of a $50 \mathrm{HPF}$ embryo showing that sema4E is expressed by the epithelial cells at the boundaries of each pharyngeal arch. C, Lateral view of a 50 HPF is/1:gfp transgenic embryo double-labeled for sema4E expression in the pharyngeal arches by in situ hybridization (blue) and anti-GFP for labeling branchiomotor axons (brown). Branchiomotor axons extend between the sema4E-expressing pharyngeal epithelial cells. Here and in D, arrowheads mark the boundaries of the pharyngeal arches. D, Lateral view of a $50 \mathrm{HPF}$ is/1:gfp transgenic embryo double-labeled with zn5 antibody for the pharyngeal epithelial cells (brown) and anti-GFP with metal intensification for branchiomotor axons (black). In each panel, anterior is to the left, and dorsal is at the top. Scale bars, $20 \mu \mathrm{m}$. motor neurons extend into the first gill arch; and axons of $\mathrm{nX}$ gill motor neurons extend into the second to fifth gill arches (Chandrasekhar et al., 1997; Higashijima et al., 2000). Branchiomotor neurons do not express sema4E (Halloran et al., 1998), but the pharyngeal arches begin to express sema4E at $22 \mathrm{HPF}$, and it is expressed strongly by the epithelium of the arches by $26 \mathrm{HPF}$ $(n=60$; Fig. $1 A)$. Pharyngeal arch expression of sema4E correlates well with outgrowth by branchiomotor axons, because the earliest branchiomotor axons, the trigeminal and facial motor axons, extend out of the hindbrain at $\sim 24 \mathrm{HPF}$ and are beginning to approach their pharyngeal arch targets (respectively, the mandibular and hyoid arches) by 28 HPF (Higashijima et al., 2000).

At later stages, expression of sema4E by the epithelium of the pharyngeal arches can be clearly seen bordering the pharyngeal arches $(n=40$; Fig. $1 B$ ), with branchiomotor axons extending between the rows of sema4E-positive epithelial cells $(n=20$; Fig. $1 C)$. The relationship between branchiomotor axons and sema4E-positive arch epithelia was demonstrated by examination of sema4E expression in isl1:gfp transgenic embryos that express GFP in the branchiomotor axons (Higashijima et al., 2000). When distribution of the DM-GRASP protein was assayed with the zn5 antibody (Fashena and Westerfield, 1999) in isl1:gfp embryos, the arch epithelium was immunoreactive for DM-GRASP, and the branchiomotor axons extended between the epithelial cells $(n=20$; Fig. $1 D)$. This correlation suggests that Sema4E is expressed by the DM-GRASP-positive arch epithelium and may restrict the facial and gill motor axons to the regions between the arch epithelia via a repulsive action.

A
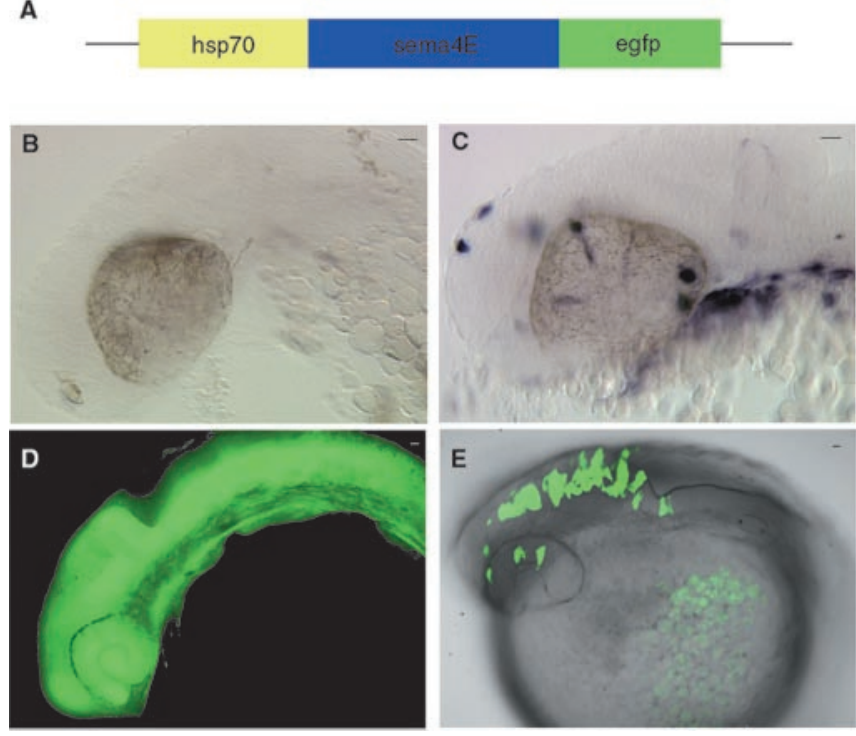

Figure 2. Sema4E ${ }^{\mathrm{GFP}}$ fusion protein is expressed by both $h s p 70: s e m a 4 E^{g f p}$ constructinjected embryos and stable $h s p 70$ :sema4 $E^{g f p}$ transgenic embryos after heat induction. $A$, Schematic of the $h$ sp 70:sema $4 E^{g f p}$ expression construct. $B-E$, Side views showing whole-mounted embryos, with anterior to the left and dorsal at the top. $B$, In situ hybridization of a $25 \mathrm{HPF}$ embryo injected with the hsp70:sema4E ${ }^{\text {ffp }}$ construct and not heat-induced, showing that sema $4 E$ is not expressed ectopically without heat induction. Here and in $C$, the staining reaction was limited to $20 \mathrm{~min}$, which was not long enough to reveal endogenous sema4E expression but was long enough to detect induced ectopic sema4E expression. C, In situ hybridization of a 25 HPF embryo injected with the hsp70:sema $4 E^{g f p}$ construct and heat-induced at $22 \mathrm{HPF}$, showing heat-induced ectopic expression of sema4E. D, Sema4E ${ }^{\text {GFP }}$ fusion protein is expressed ubiquitously in a 25 HPF hsp70:sema4Egfp transgenic embryo after heat induction at 22 HPF. E, A 26 HPF wild-type host embryo after transplantation of transgenic cells from $h s p 70: s e m a 4 E^{g f p}$ donor embryos, showing Sema $4{ }^{\mathrm{EGF}}$-expressing donor cells after heat induction at $22 \mathrm{HPF}$. Scale bars, $20 \mu \mathrm{m}$. 

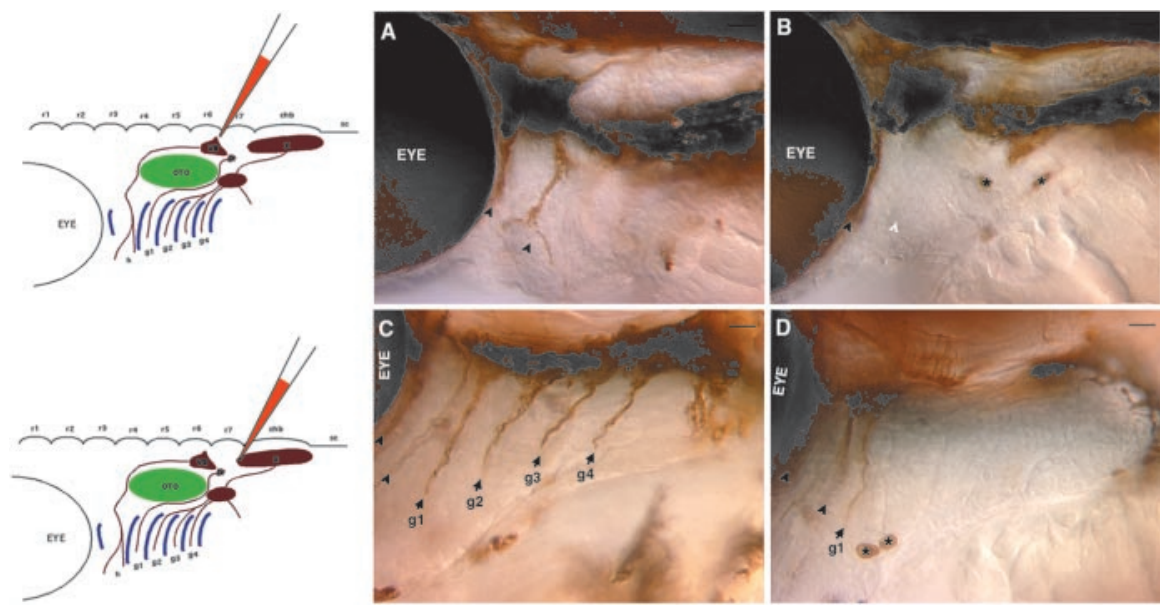

Figure 3. Facial and gill motor axons are inhibited by ubiquitous misexpression of sema4E in $h s p 70: s e m a 4 E^{g f p}$ transgenic embryos. All panels show lateral views of embryos, with anterior to the left and dorsal at the top. Branchiomotor axons were labeled by Dil injections into the anterior (top left diagram) or posterior (bottom left diagram) hindbrain, followed by photoconversion to label the facial motor axons and gill motor axons, respectively. $A$, In $48 \mathrm{HPF}$ control embryos, the facial motor nerve extends into the ventral hyoid arch, with a branch in the midhyoid region of the arch. The anterior arrowhead marks the trigeminal motor axons in the mandibular arch, and the posterior arrowhead marks the facial motor axons in the hyoid arch. $B, \ln$ a $48 \mathrm{HPF}$ hsp70:sema4E ${ }^{\text {ffp }}$ transgenic embryo heat-induced at 17 and $29 \mathrm{HPF}$, facial motor axons failed to exit the hindbrain, whereas the trigeminal axons (black arrowhead) were normal. The position of the facial motor axons had they grown out is depicted by the white arrowhead. C, Gill motor axons (arrows) extend into ventral portions of the gill arches in $50 \mathrm{HPF}$ wild-type embryos. The anterior arrowheads denote the trigeminal and facial axons. D, Extension of gill motor axons is highly retarded in $50 \mathrm{HPF} h s p 70$ : sema $4 E^{g f p}$ transgenic embryos after heat induction at $35 \mathrm{HPF}$. In this case, the gill 2-4 motor axons failed to exit the hindbrain, whereas gill 1 (g1), facial (arrowhead), and trigeminal (arrowhead) motor axons were normal. Asterisks in $B$ and $D$ indicate red blood cells in the arch blood vessels that were labeled because of endogenous peroxidase activity. Scale bar, $20 \mu \mathrm{m}$.

\section{Misexpression of sema4E is inducible in $h s p 70: s e m a 4 E^{g f p}$ transgenic fish}

To study the in vivo action of Sema4E, we generated $h s p 70: s e m a 4 E^{g f p}$ transgenic lines of zebrafish (Fig. 2). sema4E was inserted into the expression vector pHSP70/4:EGFP (Halloran et al., 2000), which contains the zebrafish $h s p 70$ promoter, to generate an $h s p 70$ : sema $4 E^{g f p}$ construct. When this construct was injected into one- to four-cell-stage embryos and the embryos heat-induced at $22 \mathrm{HPF}$, GFP fluorescence and presumably Sema4 $\mathrm{E}^{\mathrm{GFP}}$ were induced in a mosaic pattern in the injected embryos $(n=200)$. This was reinforced by the finding that sema $4 E$ mRNA was expressed mosaically after heat induction of injected embryos $(n=20)$ in addition to its normal expression pattern. GFP was induced mosaically, presumably because of nonuniform segregation of the construct as the injected cells divided. Without heat induction, no GFP $(n=200)$ or sema4E $(n=20)$ was expressed ectopically in the injected embryos. Thus, the $h s p 70: s e m a 4 E^{g f p}$ construct is heatinducible, with no detectable expression in the absence of heat induction as measured by GFP fluorescence.

Having established that the construct was inducible, we generated transgenic lines by injecting $h s p 70: s e m a 4 E^{g f p}$ into recently fertilized embryos and raising them to sexual maturity. The mature fish were then mated in a pair-wise manner, and their F1 progeny were screened for the presence of the transgene by PCR. Of 60 fish assayed, 6 were PCR-positive for the transgene. Three of the six founders identified by PCR produced progeny that exhibited GFP fluorescence by the end of the $1 \mathrm{hr}$ heat induction period (Fig. 2D). The induced expression of GFP was seen throughout the embryos, and the expression strengths varied among the three expressing lines. No GFP fluorescence was detectable when transgenic embryos were not heat induced. Line hsp70:sema4E $E^{g f p}$ was the most robust; homozygotes of this line were raised to sexual maturity, and their homozygous progeny were used for overexpression analysis. Western blots with anti-GFP of protein extracted from $h s p 70: s e m a 4 E^{g f p}$ transgenic embryos showed that Sema4E ${ }^{\text {GFP }}$ clearly was present $1 \mathrm{hr}$ after the end of heat induction initiated at $22 \mathrm{HPF}$ for $1 \mathrm{hr}$, peaked $5 \mathrm{hr}$ later, and was still elevated 12 hr after induction (data not shown). Thus, ubiquitous misexpression of Sema $4 \mathrm{E}^{\mathrm{GFP}}$ is quickly heat-induced, with levels elevated for at least $12 \mathrm{hr}$.

Expression of the transgene by a subset of cells in an embryo could be achieved by transplanting cells from an hsp70: sema $4 E^{g f p}$ transgenic embryo at $4-5 \mathrm{HPF}$ into nontransgenic embryos at the same stage. After additional development and then heat induction, donor cells in the host embryo exhibited GFP fluorescence (Fig. $2 E)$. Therefore, hsp70:sema $4 E^{g f p}$ transgenic lines can be used to manipulate sema4E expression both spatially and temporally.

\section{Ubiquitous induction of Sema4E retards branchiomotor axons}

To test whether Sema4E is a guidance cue for branchiomotor axons, we first examined how branchiomotor axons were affected by induced ubiquitous expression of sema4E. The trigeminal and facial motor neurons project axons (20-21 HPF) before the gill motor neurons, and by $24 \mathrm{HPF}$, the first branchiomotor axons exit the hindbrain (Higashijima et al., 2000). Therefore, because heat induction of $h s p 70: s e m a 4 E^{g f p}$ embryos elevates Sema4E ${ }^{\mathrm{GFP}}$ for $\sim 12 \mathrm{hr}$, hsp70:sema4E sf $^{g f \mathrm{em}-}$ bryos were heat-induced at $17 \mathrm{HPF}$ and reinduced at $29 \mathrm{HPF}$ to maintain the Sema4E protein level during the period of axonal outgrowth; they were then assayed at $48 \mathrm{HPF}$ to determine whether ubiquitous expression of sema $4 E$ would affect trigeminal and facial motor axons. Gill motor axons are projected from the cell bodies at $36 \mathrm{HPF}$, and the axons exit the hindbrain at $\sim 40$ HPF (Higashijima et al., 2000). Therefore, to assay effects of Sema4E on gill motor axons, transgenic embryos were heatinduced at $35 \mathrm{HPF}$ and assayed at $48 \mathrm{HPF}$.

Ubiquitous expression of Sema4E retarded outgrowth by both facial and gill motor axons but not trigeminal motor axons (Fig. $3)$. By $48 \mathrm{HPF}$, wild-type embryos $(n=16)$ and uninduced $h s p 70$ : sema $4 E^{g f p}$ transgenic embryos $(n=16)$ had trigeminal axons that extended into the mandibular arch and facial motor axons that branched and extended into the hyoid arch. In contrast, in heatinduced $h s p 70: s e m a 4 E^{g f p}$ embryos, facial axons failed to exit the hindbrain (11 of 16 embryos), and when they did extend into the hyoid arch, they were retarded ( 5 of 16 embryos), whereas the trigeminal axons were normal in all cases. As expected, a similar phenotype was observed among gill motor axons. In both wild-type $(n=20)$ and uninduced $h s p 70: s e m a 4 E^{g f p}(n=20)$ embryos, gill motor axons extended to the ventral-most part of the gill arches at 48 HPF. In heat-induced $h s p 70: s e m a 4 E^{g f p}$ embryos, most gill motor axons failed to extend out of the hindbrain ( 28 of 35 embryos). For the axons that did extend into the gill arches, the growth was highly retarded ( 7 of 35 embryos). These results suggested that the growth of both facial and gill motor axons was retarded by the presence of Sema4E in the environment, and this retardation was likely the 
consequence of a repulsive action of Sema4E toward facial and gill axons.

\section{Branchiomotor axons are inhibited by clusters of cells that misexpress sema4E}

Retardation of branchiomotor axons after ubiquitous expression of Sema4E suggests that Sema4E is a repulsive signal for branchiomotor growth cones. Alternatively, because Sema4E is a transmembrane protein with a short intracellular domain and is expressed by the branchiomotor neurons in the transgenic embryos after heat induction, it could potentially be a component of a receptor for an attractive or repulsive molecule that is normally expressed in their environment. To more directly test whether Sema4E acts as an extrinsic repulsive factor, we generated mosaic embryos in which groups of cells not including the branchiomotor neurons misexpressed Sema4E. If Sema4E acts as a repulsive signal, then misexpression of Sema4E by groups of cells in the pathway of branchiomotor axons should exert a local repulsive effect.

To generate mosaic embryos, we transplanted cells from hsp70:sema $4 E^{g f p}$ transgenic donors at 4-5 HPF into age-matched wild-type host embryos (Fig. 2E). After heat induction, transgenic cells could be identified readily in the mosaics by their expression of Sema4E GFP. Sixty mosaic embryos were generated and heat-induced at 28 and $35 \mathrm{HPF}$ and assayed at $48 \mathrm{HPF}$. Of the 60 mosaic embryos, 3 had transplanted transgenic cells located in the region of the posterior pharyngeal arches near the hindbrain but not in the region of the gill motor neurons in the hindbrain. In each case, transgenic cells induced to express Sema4E were found at or near the exit point of one of the gill motor nerves, and that motor nerve failed to exit the hindbrain, whereas the others were unaffected (Fig. 4). This result suggests that Sema4E found in the environment of the branchiomotor axons can repulse these axons.

\section{Absence of Sema4E induces facial axons to defasciculate and make errors}

To determine whether Sema4E expressed by the pharyngeal arches is required for normal pathfinding by branchiomotor axons, we injected antisense MOs (Summerton, 1999; Heasman et al., 2000) against sema4E into recently fertilized embryos to "knock down" Sema4E. Antisense MOs effectively and specifically block the translation of the targeted mRNAs in zebrafish (Nasevicius and Ekker, 2000). Sema4E antisense MOs were designed against $5^{\prime}$ sequences that included the sema4E start codon. Four nucleotides of the antisense oligonucleotides were changed randomly to generate the control MOs. To test whether antisense Sema4E MO could effectively knock down Sema4E protein synthesis, we injected the antisense or control MO into recently fertilized $h s p 70: s e m a 4 E^{g f p}$ embryos, heat induced them at $22 \mathrm{HPF}$, and assayed them for induction of Sema $4 \mathrm{E}^{\mathrm{GFP}}$ by fluorescence at $28 \mathrm{HPF}$. GFP fluorescence was reduced significantly in $74 \%$ of the Sema4E MO-injected transgenic embryos $(n=96)$, whereas all Sema4E control MO-injected transgenic embryos $(n=61)$ showed GFP fluorescence comparable with that of uninjected transgenic embryos (Fig. 5A,B).

To test the specificity of knockdown, we injected Sema4E antisense or control MO into recently fertilized embryos from a transgenic line in which another semaphorin was heat inducible, hsp70: $g f p$ sema $A 1^{m y c}$. In this line, $g f p$ was placed between the signal sequence and Sema domain of sema3A1. Thus, the transgene contained sequences that are normally targets of antisense MO. After heat induction at $22 \mathrm{HPF}$, all Sema4E antisense $(n=68)$
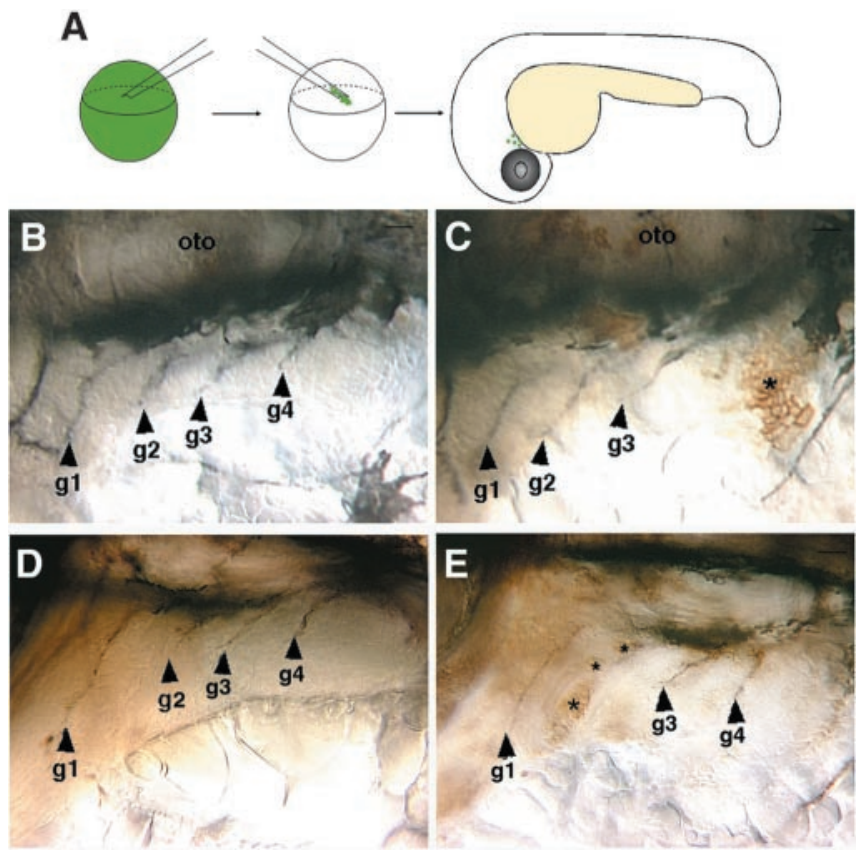

Figure 4. Outgrowth by wild-type host gill motor axons was inhibited by Sema4Eexpressing cells transplanted from donor $h s p 70: s e m a 4 E^{g f p}$ embryos into nontransgenic hosts. $A$, Schematic showing how cells were transplanted from $h s p 70$ :sema $4 E^{g f p}$ embryos into nontransgenic embryos. See Materials and Methods for details. The host embryos were heatinduced at 28 and $35 \mathrm{HPF}$, and the gill motor axons (anti-SV2) and location of the Sema4E GFP. expressing cells (anti-GFP) were analyzed at 48 HPF. B, D, In control mosaic embryos that contained no GFP-positive cells within the arches, the gill motor axons ( $g 1-g 4)$ have extended normally into their respective gill arches. C, In a mosaic embryo, a group of Sema4E ${ }^{\text {GFP }}$ expressing cells (asterisk) transplanted to the exit point for the gill 4 motor axons inhibited the host g4 but not the g1-g3 motor axons from exiting the hindbrain. $E$, In another mosaic

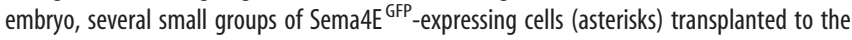
pathway of the $\mathrm{g} 2$ motor axons inhibited the host $\mathrm{g} 2$ but not $\mathrm{g} 1, \mathrm{~g} 3$, or g4 axons from exiting the hindbrain. Scale bar, $40 \mu \mathrm{m}$.

and control $(n=55)$ MO-injected $h s p 70:{ }^{g f p}$ sema3A1 ${ }^{m y c}$ embryos showed normal levels of GFP fluorescence at $28 \mathrm{HPF}$ (Fig. 5C,D). These results demonstrate that Sema4E antisense MO can effectively and specifically knock down induction of the sema $4 E$ transgene in vivo and presumably expression of the endogenous sema4E as well.

To examine the effects of knocking down Sema4E on branchiomotor axons, recently fertilized wild-type embryos were injected with Sema4E antisense and control MO. The trigeminal and facial motor axons were then labeled with DiI, followed by photo-oxidation in DAB at $48 \mathrm{HPF}$. In control MO-injected embryos, the trigeminal and facial motor axons were normal in all cases $(n=30$; Fig. $5 E)$. Conversely, in antisense MO-injected embryos, the facial but not the trigeminal motor axons were affected adversely $(n=30$; Fig. $5 F)$ in $50 \%$ of cases. Although the facial motor axons extended within the hyoid arch, the axons were highly defasciculated, branched, or both and followed aberrant pathways. These results suggest that Sema4E expressed by the epithelium of the hyoid arch is necessary for normal pathfinding by the facial motor axons within the hyoid arch.

Induction of Sema4E in Sema4E antisense MO-injected hsp70: sema4E $E^{g f p}$ embryos can inhibit the knockdown phenotype Because knockdown of Sema4E causes facial motor axons to defasciculate and follow aberrant pathways, it should be possible to prevent the knockdown-induced pathfinding defects and instead 

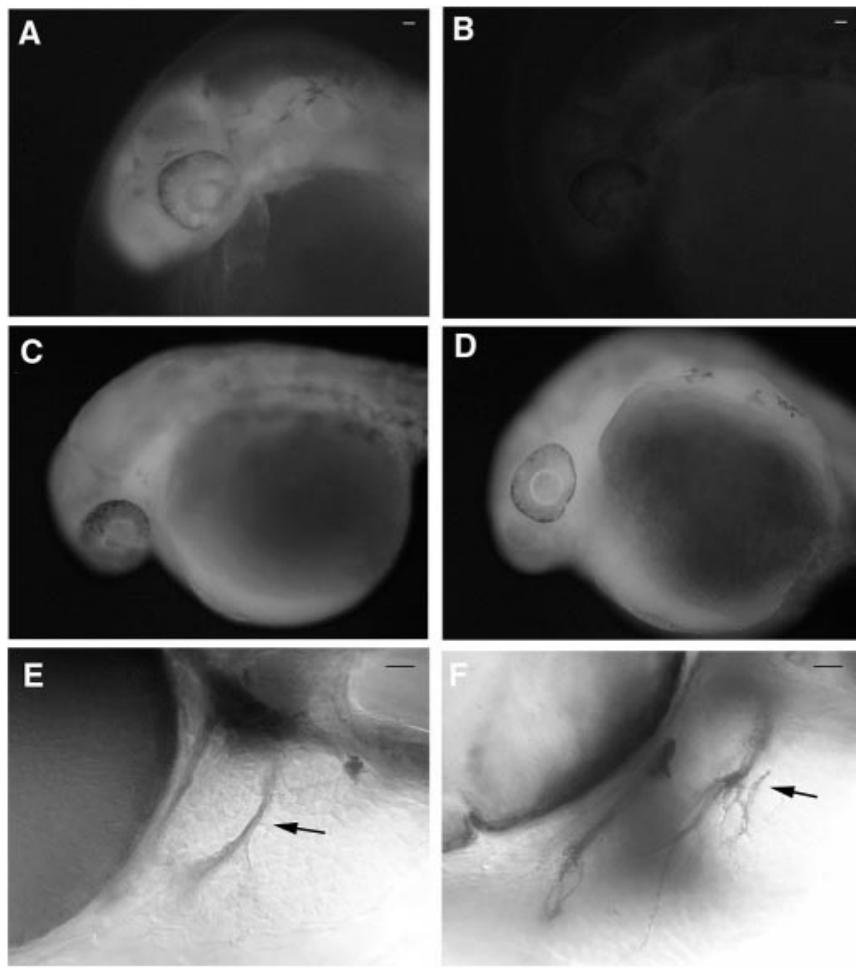

Figure 5. Antisense sema4E MOs effectively and specifically knock down expression of Sema4E and lead to defasciculation and aberrant outgrowth by facial motor axons. In $A-D, M 0$ was injected at one- to eight-cell stage, heat-induced at $22 \mathrm{HPF}$, and assayed for fusion protein expression by GFP fluorescence at $28 \mathrm{HPF}$. A, Heat induction of Sema4E ${ }^{\mathrm{GFP}}$ was not blocked by injection of control sema4E M0 into hsp70:sema4 ${ }^{g f p}$ embryos. B, Heat induction of Sema $4{ }^{\text {GFP }}$ was reduced significantly by injection of antisense sema4E M0 into hsp70:sema4E ${ }^{g f p}$ embryos. $C$, Heat induction of ${ }^{\text {GFP Sema } 3 A 1} 1^{\text {myc }}$ was not blocked by injection of control sema4E M0 into hsp70: ${ }^{\text {gfp }}$ sema3A1 ${ }^{\text {myc }}$ embryos. D, Heat induction of ${ }^{\text {GFP }}$ Sema3A1 ${ }^{\text {myc }}$ was not blocked by injection of antisense sema4E M0 into hsp70: ${ }^{g f p}$ sema3A1 ${ }^{m y c}$ embryos. E, In a control sema4E M0injected wild-type embryo (48 HPF), facial motor axons (arrow) are comparable with those of noninjected wild-type embryos. Trigeminal and facial motor axons were labeled with Dil and photoconverted. $F$, In an antisense sema4E M0-injected embryo (48 HPF), facial motor axons (arrow) were defasciculated and strayed from their normal pathway. Scale bar, $20 \mu \mathrm{m}$.

induce a ubiquitous misexpression phenotype by resupplying Sema4E. To do this, we knocked down Sema4E by injecting Sema4E antisense MO into recently fertilized $h s p 70: s e m a 4 E^{2 f p}$ embryos and then heat induced Sema4E at 25 HPF to resupply Sema4E. Furthermore, we examined the specificity of potential reversals of the knockdown phenotype by injecting Sema4E antisense MO into hsp70: ${ }^{8 f}$ sema3A1 ${ }^{m y c}$ embryos and heat inducing another semaphorin, Sema3A1.

When hsp70:sema4E $E^{g f p}$ embryos were heat-induced at 25 and $38 \mathrm{HPF}$, the facial motor axons had extended into the hyoid arch at $48 \mathrm{HPF}$ but were delayed (30 of 30 embryos) compared with wild-type embryos $(n=30)$ that were subjected to the same heat induction regimen (Fig. 6, compare $A, C$ ). The facial motor axons were not inhibited from extending out of the hindbrain as in the previous ubiquitous expression experiment, presumably because of later induction of Sema4E in this experiment (25 and $38 \mathrm{HPF}$ ) than in the previous experiment (17 and $29 \mathrm{HPF}$ ) (compare Figs. $6 C, 3 B)$. When Sema4E antisense MO was injected into hsp70: sema4 $E^{g f p}$ embryos and then heat-induced at $25 \mathrm{HPF}$, the facial motor axons were not highly defasciculated and had extended along their normal pathway (30 of 30 embryos; Fig. 6D). The extent of outgrowth was comparable to ubiquitous induction at 25 and $38 \mathrm{HPF}$ in $h s p 70: s e m a 4 E^{g f p}$ embryos not injected with the
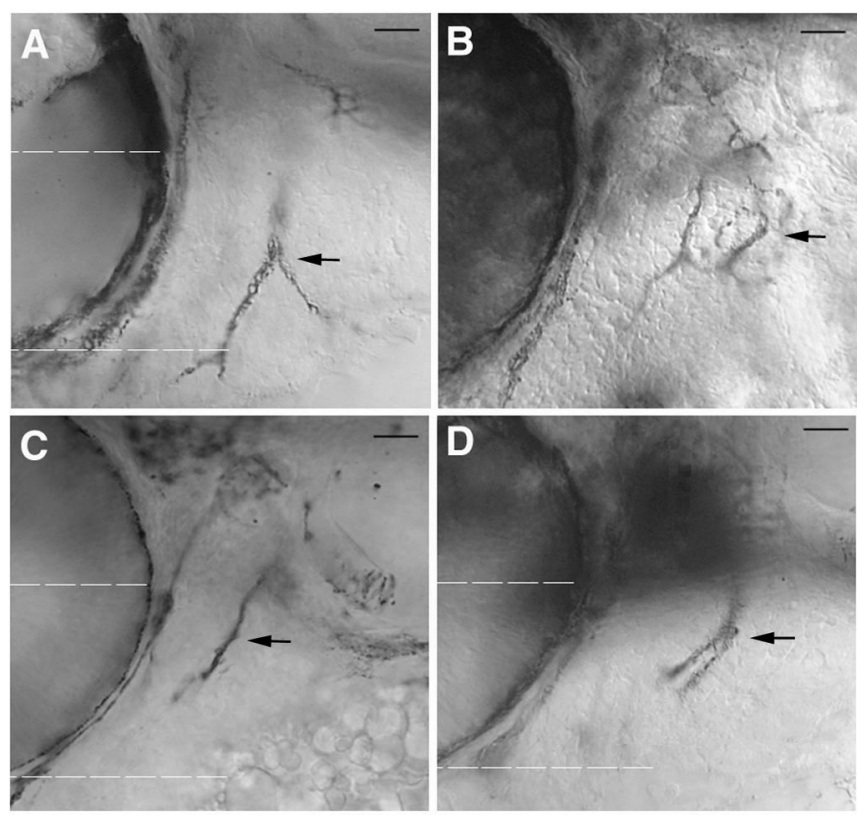

Figure 6. Induced expression of Sema4E blocks the defasciculation and aberrant outgrowth of facial motor axons caused by Sema4E knockdown and instead induces retardation of facial motor axons. All panels show lateral views of facial motor axons (arrows) that were labeled with anti-SV2 (anterior is to the left, and dorsal is at the top) at 48 HPF. A, Facial motor axons are fasciculated and followed their normal pathway in a control embryo that was injected with control sema $4 E \mathrm{MO}$ and heat-induced at 25 and $38 \mathrm{hr}$. Dashed lines are added for comparison of the extent of outgrowth by facial motor axons in $A, C$, and $D$. $B$, Facial motor axons are defasciculated, followed aberrant pathways, or both in an $h s p 70:{ }^{g f p}$ sema $3 A 7^{m y c}$ transgenic embryo that was injected with antisense sema4E M0 and heat-induced at $25 \mathrm{HPF}$ to express Sema3A1. C, Facial motor axons are retarded in an hsp70:sema4Egfp transgenic embryo that was heatinduced at 25 and $38 \mathrm{HPF}$ compared with control embryos (compare A, O. D, Outgrowth by the facial motor axons is not defasciculated, does not follow aberrant pathways, or both in an hsp70:sema4E ${ }^{g f p}$ embryo that was injected with antisense sema4E M0 and heat-induced at 25 HPF. The extent of outgrowth by the facial motor axons is comparable to that seen after heat induction of $h$ sp 70:sema $4 E^{g f p}$ embryos at 25 and 38 HPF that had not been injected with antisense sema4E M0 (compare C, D). Scale bar, $20 \mu \mathrm{m}$.

Sema4E antisense MO (Fig. 6C). Thus, resupplying Sema4E inhibited the knockdown phenotype and instead produced the ubiquitous expression phenotype. Furthermore, the facial motor axons were defasciculated and followed aberrant pathways when hsp70: ${ }^{\& f p}$ sema3A1 $1^{m y c}$ embryos that had been injected with the Sema4E antisense MO were heat-induced at 25 HPF (16 of 30 embryos; Fig. $6 \mathrm{~B}$ ). Therefore, inhibition of the Sema4E knockdown phenotype shows specificity, because Sema4E but not Sema3A1 was able to inhibit the Sema4E knockdown-induced outgrowth errors. These results suggest that the defasciculation and aberrant pathways followed by facial motor axons after injection of the Sema4E antisense MO were caused by the lack of endogenous Sema4E.

\section{Neither induction of ubiquitous misexpression nor knockdown of Sema4E affects the specification and} patterning of branchiomotor neurons and pharyngeal arches Both gain-of-function and loss-of-function analyses of Sema4E suggest that Sema4E expressed by the pharyngeal arch epithelium acts to guide branchiomotor axons via an inhibitory activity. Alternatively, the gain-of-function and loss-of-function axonal phenotypes could be secondary effects of aberrant specification or patterning of the branchiomotor neurons themselves or their target pharyngeal arches caused by ubiquitous expression or knockdown of Sema4E. A change in the fate or patterning of the 
branchiomotor neurons or the pharyngeal arches might be expected to affect axonal outgrowth into the arches.

To determine whether induction of ubiquitous expression or knockdown of Sema4E affects the specification or patterning of the branchiomotor neurons, we assayed for branchiomotor marker genes after induced expression or knockdown of Sema4E. We examined the expression of transcription factors required by motor neurons, the islet proteins, and expression of a gene encoding an axonal glycoprotein that promotes axon growth, tag-1, in the hindbrain after Sema4E induction or knockdown. Islet proteins are among the earliest transcription factors expressed by motor neurons, including zebrafish branchiomotor neurons (Korzh et al., 1993; Tsuchida et al., 1994; Appel et al., 1995; Chandrasekhar et al., 1997), and islet1 function is required for the production of motor neurons (Pfaff et al., 1996). tag- 1 is an Ig superfamily member that encodes for an axonal protein that promotes axonal outgrowth (Furley et al., 1990) and is also expressed by zebrafish branchiomotor neurons (Warren et al., 1999; Chandrasekhar et al., 1997). Neither heat induction of Sema4E in hsp70:sema4E $2 f p$ embryos nor morpholino knockdown of Sema4E in wild-type embryos affected the expression pattern of the islet proteins ( $n=40$ for heat induction at $35 \mathrm{HPF} ; n=$ 6 for heat induction at 17 and $29 \mathrm{HPF} ; n=$ 40 for morpholino knockdown) or tag-1 ( $n=40$ for heat induction at $35 \mathrm{HPF} ; n=$ 40 for morpholino knockdown) by the branchiomotor neurons (Fig. 7). These results suggest that the specification, differentiation, and patterning of the branchiomotor neurons are not affected adversely by ubiquitous expression or knockdown of Sema4E.

To determine whether induction of ubiquitous expression or knockdown of Sema4E affects the specification or patterning of the pharyngeal arches, we assayed for expression of pharyngeal arch marker genes. We examined a transcription factor, $d l x 3$, that is expressed by the pharyngeal arches (Ekker et al., 1992; Akimenko et al., 1994) and DM-GRASP, an Ig superfamily member that is made by the epithelial cells of the pharyngeal arches, the very cells that express sema4E (Fig. 1D). Neither heat induction of Sema4E in hsp70:sema4E ${ }^{g f p}$ embryos nor morpholino knockdown of Sema4E in wild-type embryos perturbed the expression pattern of $d l x 3(n=40$ for heat induction at 35 HPF; $n=40$ for morpholino knockdown) or DM-GRASP ( $n=$ 40 for heat induction at $35 \mathrm{HPF} ; n=40$ for morpholino knockdown) in the pharyngeal arches (Fig. 8). Furthermore, the pattern of blood vessels within the pharyngeal arches $(n=10$ for heat induction at $35 \mathrm{HPF}$ ) and the pattern of cartilage given rise to by the arches $(n=10$ for heat induction at 35 HPF; $n=6$ for heat
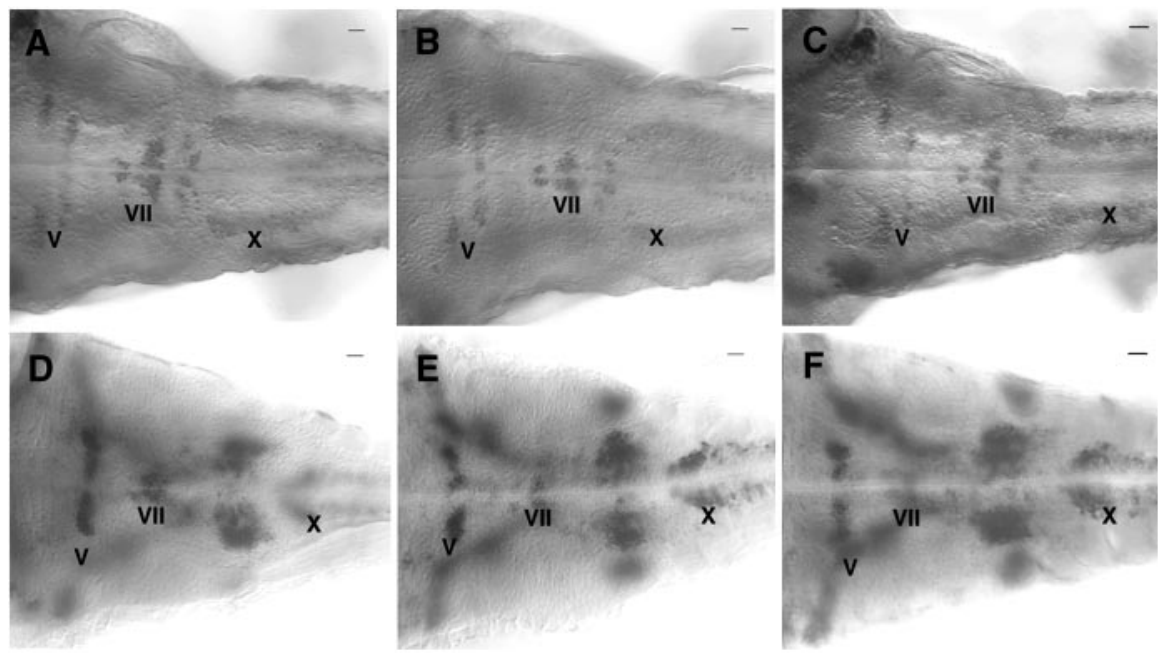

Figure 7. Neither ubiquitous induction nor knockdown of Sema4E perturbs the cell fate or patterning of branchiomoto neurons. All panels show dorsal views of a 48 HPF midbrain and hindbrain, with anterior to the left. Motor nuclei V, VII, and X are designated. $A$, Pattern of branchiomotor neurons labeled with anti-islet in a control embryo. $B$, The pattern of islet-positive branchiomotor neurons is normal in a wild-type embryo injected with antisense sema4E MO. D, The pattern of branchiomotor neurons labeled by in situ hybridization to a tag-1 antisense riboprobe in a control embryo. $E$, The pattern of tag-1-positive branchiomotor neurons is normal in an hsp70:sema4Egfp embryo that was heat-induced at 35 HPF. F, The pattern of tag-1-positive branchiomotor neurons is normal in a wild-type embryo injected with antisense sema4E M0. Scale bar, $20 \mu \mathrm{m}$.
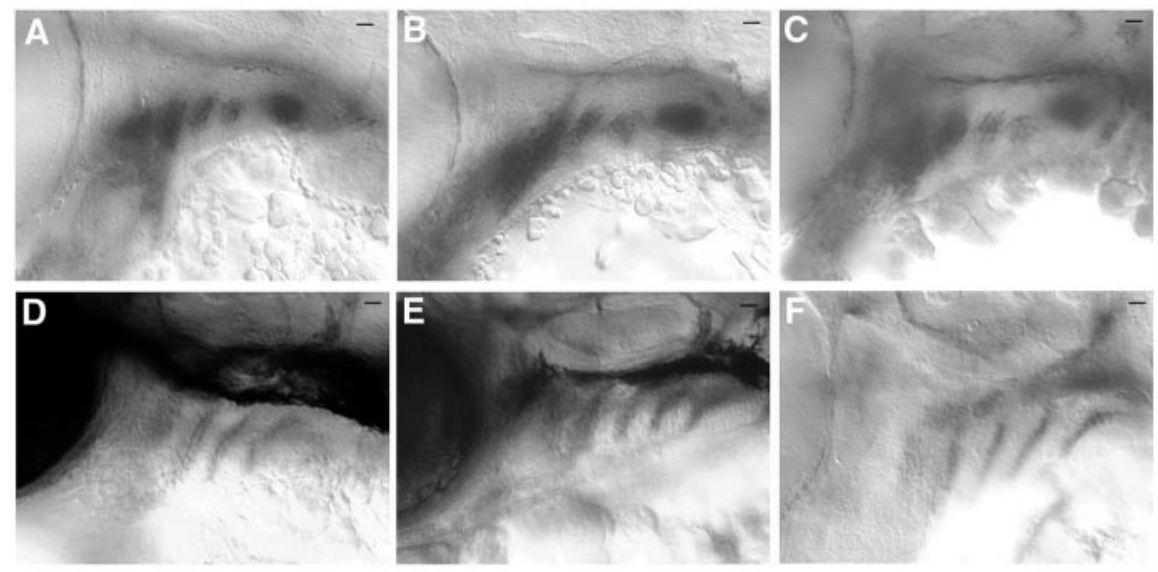

Figure 8. Neither ubiquitous induction nor knockdown of Sema4E perturbs the cell fate or patterning of the pharyngea arches. All panels show side views of $48 \mathrm{HPF}$ embryos. A, Pattern of $d l \times 3$-positive cells in the pharyngeal arches shown by in situ hybridization in a control embryo. $B$, The pattern of $d 1 \times 3$-positive cells is normal in an hsp70:sema4E ${ }^{g f p}$ embryo that was heatPattern of DM-GRASP-positive cells shown by anti-zn5 labeling of a control embryo. E, The pattern of DM-GRASP-positive cells is normal in an hsp70:sema4E ${ }^{g f p}$ embryo that was heat-induced at 35 HPF. F, The pattern of DM-GRASP-positive cells is normal in a wild-type embryo injected with antisense sema4E MO. Scale bar, $20 \mu \mathrm{m}$.

induction at 17 and $29 \mathrm{HPF}$ ) was normal after heat induction of Sema4E (Fig. 9). These results suggest that patterning of the pharyngeal arches is not affected by ubiquitous expression or knockdown of Sema4E. Thus, ubiquitous expression and knockdown of Sema4E appear to affect outgrowth by branchiomotor axons directly via a repulsive action.

\section{Discussion}

\section{Sema4E is a class 4 semaphorin with a role in} neural development

The gain-of-function and loss-of-function results demonstrate that Sema4E guides facial motor axons by a repulsive action. Furthermore, retardation of outgrowth by gill motor axons after 

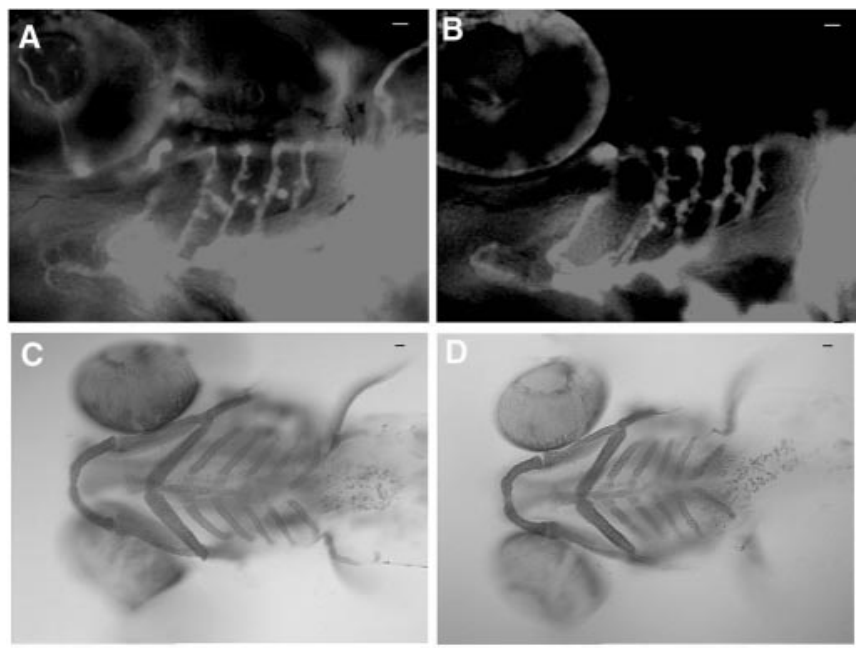

Figure 9. Ubiquitous induction of Sema4E does not affect the pattern of blood vessels in the pharyngeal arches or the pattern of cartilage that is derived from the arches. $A$, Lateral view showing the pattern of tetramethylrhodamine isothiocyanate dextran-labeled blood vessels in the pharyngeal arches in a $48 \mathrm{HPF}$ control embryo. $B$, Lateral view showing that the pattern of blood vessels is normal in an hsp70:sema4E ${ }^{g f p}$ embryo that was heat-induced at $35 \mathrm{HPF}$. C, Ventral view of the head showing the pattern of alcian blue-labeled cartilage in a 5-d-old control larva. D, Ventral view of the head showing that the pattern of alcian blue-labeled cartilage is normal in a 5-d-old $h s p 70$ :sema $4 E^{\text {gfp }}$ embryo that was heat-induced at $35 \mathrm{HPF}$. Scale bar, $20 \mu \mathrm{m}$.

misexpression of Sema4E or interaction with ectopic Sema4Eexpressing cells is consistent with a repulsive guidance role for gill motor axons. These findings establish for the first time an in vivo role for a class 4 semaphorin within the nervous system. Although it is one of the largest classes in the semaphorin family and is expressed widely throughout the nervous system (Puschel et al., 1995; Ohoka et al., 2001; Schultze et al., 2001), no class 4 semaphorin had been known to have a nervous system function in vivo. In fact, the function of only one other class 4 semaphorin, Sema4D/CD100, was known previously. The function of Sema4D/CD100 within the immune system is well established (Hall et al., 1996; Shi et al., 2000; Delaire et al., 2001). Little is known about the function of Sema4D/CD100 and its plexin-B1 receptor within the brain, although both are expressed in the brain (Furuyama et al., 1996; Hall et al., 1996; Maestrini et al., 1996). To date, examination of Sema4D/CD100 knock-out mice has not revealed any clues about its role in brain development or function. Sema4D/CD100-deficient mice are viable and appeared normal in histological and behavioral examinations (Shi et al., 2000). Given the present findings for Sema4E and the well established roles of other classes of semaphorins within the nervous system, a closer inspection of Sema4D/CD100-deficient mice may be warranted.

\section{Do semaphorins act coordinately to regulate pathfinding by branchiomotor axons?}

The initial motivation for examination of branchiomotor axons as a target for Sema4E was that Sema4E is expressed by the epithelium of the pharyngeal arches (Halloran et al., 1998). Two other semaphorins are also expressed by the pharyngeal arches in zebrafish. Sema3A1 is expressed by the epithelium of the arches (Yee et al., 1999) at approximately the same time Sema4E is expressed by the same cells, and Sema3D is expressed by a subset of cells within the arch mesenchyme (Halloran et al., 1999). Thus, Sema3A1, Sema4E, and Sema3D are expressed coordinately in the arches. Because the branchiomotor axons extend within the mesenchyme of the arches and do not cross over the epithelial boundaries of the arches, it is possible that Sema3A1 and Sema3D may act cooperatively with Sema4E in guiding branchiomotor axons within the pharyngeal arches. Specifically, we might expect Sema3A1 to be repulsive and Sema3D to be attractive to branchiomotor axons.

Despite the fact that most class 3 semaphorins act repulsively, two showed that they can also attract axons in vitro. Sema3C repels sympathetic axons but attracts cortical axons (Bagnard et al., 1998), and Sema3F repels sympathetic and hippocampal axons but attracts olfactory bulb axons (de Castro et al., 1999). Additionally, the response of growth cones to Sema3A can be changed from repulsion to attraction depending on the level of cGMP within the growth cone (Song et al., 1998). Thus, there are precedents for an attractive activity of semaphorins that is in accord with a putative attractive activity for Sema3D on branchiomotor growth cones.

The hypothesis that Sema3A1 may be repulsive for branchiomotor axons is consistent with findings that Sema3A1 is repulsive to spinal motor axons and posterior lateral line axons in zebrafish (Shoji et al., 1998; Yee et al., 1999; Halloran et al., 2000). Furthermore, cranial nerves are defasciculated in both Sema3A knockout mice (Taniguchi et al., 1997) and neuropilin-1 knock-out mice (Kitsukawa et al., 1997), which is consistent with a role for Sema3A in guidance of branchiomotor axons. However, the fact that induction of ubiquitous expression of Sema3A1 failed to prevent defasciculation and aberrant outgrowth of the facial motor axons induced by morpholino knockdown of Sema4E suggests that Sema3A1 may not have a dominant action on facial motor axons.

\section{Sema4E may act to restrict other axons within the nervous system}

Functional analysis of Sema4E suggests that it acts as a barrier for branchiomotor axons at the boundaries of the pharyngeal arches. sema $4 E$ is also expressed at boundaries in several other locations in the zebrafish embryo (Halloran et al., 1998). Because sema4E is expressed by the epithelium of the developing pectoral fin, it may serve to restrict fin motor axons to the developing fin muscles. Similarly, expression of sema4E by the caudal and medial boundary of the optic tectum at stages when retinal ganglion axons are invading the tectum suggests that it may restrict retinal axons to the tectum. Finally, sema4E is expressed by a longitudinal stripe of cells in the dorsal hindbrain and spinal cord. Because one of the major longitudinal tracts, the dorsal longitudinal fasciculus (DLF), forms adjacent to the ventral border of this expression domain, Sema4E may act to prevent DLF axons from extending more dorsally. In this way, the dorsal expression of Sema4E may determine the location of the DLF. Thus, expression of sema4E at several boundaries in the developing zebrafish suggests that a major task of Sema4E is to provide a barrier for specific axons, as it does for branchiomotor axons in the pharyngeal arches.

\section{References}

Akimenko MA, Ekker M, Wegner J, Lin W, Westerfield M (1994) Combinatorial expression of three zebrafish genes related to distal-less: part of a homeobox gene code for the head. J Neurosci 14:3475-3486.

Appel B, Korzh V, Glasgow E, Thor S, Edlund T, Dawid IB, Eisen JS (1995) Motoneuron fate specification revealed by patterned LIM homeobox gene expression in embryonic zebrafish. Development 121:4117-4125.

Bagnard D, Lohrum M, Uziel D, Puschel AW, Bolz J (1998) Semaphorins act as attractive and repulsive guidance signals during the development of cortical projections. Development 125:5043-5053. 
Chandrasekhar A, Moens CB, Warren Jr JT, Kimmel CB, Kuwada JY (1997) Development of branchiomotor neurons in zebrafish. Development 124:2633-2644.

de Castro F, Hu L, Drabkin H, Sotelo C, Chedotal A (1999) Chemoattraction and chemorepulsion of olfactory bulb axons by different secreted semaphorins. J Neurosci 19:4428-4436.

Delaire S, Elhabazi A, Bensussan A, Boumsell L (1998) CD100 is a leukocyte semaphorin. Cell Mol Life Sci 54:1265-1276.

Delaire S, Billard C, Tordjman R, Chedotal A, Elhabazi A, Bensussan A, Boumsell L (2001) Biological activity of soluble CD100. II. Soluble CD100, similarly to H-SemaIII, inhibits immune cell migration. J Immunol 166:4348-4354.

Dingerkus G, Uhler LD (1977) Enzyme clearing of Alcian Blue stained whole small vertebrates for demonstration of cartilage. Stain Technol 52:229-232.

Ekker M, Akimenko MA, Bremiller R, Westerfield M (1992) Regional expression of three homeobox transcripts in the inner ear of zebrafish embryos. Neuron 9:27-35.

Encinas JA, Kikuchi K, Chedotal A, De Castro F, Goodman CS, Kimura T (1999) Cloning, expression, and genetic mapping of Sema W, a member of the semaphorin family. Proc Natl Acad Sci USA 96:2491-2496.

Fashena D, Westerfield M (1999) Secondary motoneuron axons localize DM-GRASP on their fasciculated segments. J Comp Neurol 406:415-424.

Furley AJ, Morton SB, Manalo D, Karagogeos D, Dodd J, Jessell TM (1990) The axonal glycoprotein TAG-1 is an immunoglobulin superfamily member with neurite outgrowth-promoting activity. Cell 61:157-170.

Furuyama T, Inagaki S, Kosugi A, Noda S, Saitoh S, Ogata M, Iwahashi Y, Miyazaki N, Hamaoka T, Tohyama M (1996) Identification of a novel transmembrane semaphorin expressed on lymphocytes. J Biol Chem 271:33376-33381.

Hall KT, Boumsell L, Schultze JL, Boussiotis VA, Dorfman DM, Cardoso AA, Bensussan A, Nadler LM, Freeman GJ (1996) Human CD100, a novel leukocyte semaphorin that promotes B-cell aggregation and differentiation. Proc Natl Acad Sci USA 93:11780-11785.

Halloran MC, Severance SM, Yee CS, Gemza DL, Kuwada JY (1998) Molecular cloning and expression of two novel zebrafish semaphorins. Mech Dev 76:165-168.

Halloran MC, Severance SM, Yee CS, Gemza DL, Raper JA, Kuwada JY (1999) Analysis of a Zebrafish semaphorin reveals potential functions in vivo. Dev Dyn 214:13-25.

Halloran MC, Sato-Maeda M, Warren JT, Su F, Lele Z, Krone PH, Kuwada JY, Shoji W (2000) Laser-induced gene expression in specific cells of transgenic zebrafish. Development 127:1953-1960.

Heasman J, Kofron M, Wylie C (2000) $\beta$-catenin signaling activity dissected in the early Xenopus embryo: a novel antisense approach. Dev Biol 222:124-136.

Higashijima S, Hotta Y, Okamoto H (2000) Visualization of cranial motor neurons in live transgenic zebrafish expressing green fluorescent protein under the control of the islet-1 promoter/enhancer. J Neurosci 20:206-218.

Ho RK, Kane DA (1990) Cell-autonomous action of zebrafish spt-1 mutation in specific mesodermal precursors. Nature 348:728-730.

Inagaki S, Ohoka Y, Sugimoto H, Fujioka S, Amazaki M, Kurinami H, Miyazaki N, Tohyama M, Furuyama T (2001) Sema4C, a transmembrane semaphorin, interacts with a post-synapti8c density protein, PSD95. J Biol Chem 276:9174-9181.

Kelly WL, Bryden MM (1983) A modified differential stain for cartilage and bone in whole mount preparations of mammalian fetuses and small vertebrates. Stain Technol 58:131-134.

Kimmel CB, Ballard WW, Kimmel SR, Ullman B, Schilling TF (1995) Stages of embryonic development of the zebrafish. Dev Dyn 203:253-310.

Kitsukawa T, Shimizu M, Sanbo M, Hirata T, Taniguchi M, Bekku Y, Yagi T, Fujisawa H (1997) Neuropilin-semaphorin III/D-mediated chemorepulsive signals play a crucial role in peripheral nerve projection in mice. Neuron 19:995-1005.

Kolodkin AL, Matthes DJ, O'Connor TP, Patel NH, Admon A, Bentley D, Goodman CS (1992) Fasciclin IV: sequence, expression, and function during growth cone guidance in the grasshopper embryo. Neuron 9:831-845.

Korzh V, Edlund T, Thor S (1993) Zebrafish primary neurons initiate ex- pression of the LIM homeodomain protein Isl-1 at the end of gastrulation. Development 118:417-425.

Luo Y, Raible D, Raper JA (1993) Collapsin: a protein in brain that induces the collapse and paralysis of neuronal growth cones. Cell 75:217-227.

Maestrini E, Tamagnone L, Longati P, Cremona O, Gulisano M, Bione S, Tamanini F, Neel BG, Toniolo D, Comoglio PM (1996) A family of transmembrane proteins with homology to the MET-hepatocyte growth factor receptor. Proc Natl Acad Sci USA 93:674-678.

Nasevicius A, Ekker SC (2000) Effective targeted gene "knockdown" in zebrafish. Nat Genet 26:216-220.

Ohoka Y, Hirotani M, Sugimoto H, Fujioka S, Furuyama T, Inagaki S (2001) Semaphorin 4C, a transmembrane semaphorin, [corrected] associates with a neurite-outgrowth-related protein, SFAP75. Biochem Biophys Res Commun 280:237-243.

Pfaff SL, Mendelsohn M, Stewart CL, Edlund T, Jessell TM (1996) Requirement for LIM homeobox gene Isl1 in motor neuron generation reveals a motor neuron-dependent step in interneuron differentiation. Cell 84:309-320.

Puschel AW, Adams RH, Betz H (1995) Murine semaphorin D/collapsin is a member of a diverse gene family and creates domains inhibitory for axonal extension. Neuron 14:941-948.

Raper JA (2000) Semaphorins and their receptors in vertebrates and invertebrates. Curr Opin Neurobiol 10:88-94.

Schulte-Merker S, Ho RK, Herrmann BG, Nusslein-Volhard C (1992) The protein product of the zebrafish homologue of the mouse $\mathrm{T}$ gene is expressed in nuclei of the germ ring and the notochord of the early embryo. Development 116:1021-1032.

Schultze W, Eulenburg V, Lessmann V, Herrmann L, Dittmar T, Gundelfinger ED, Heumann R, Erdmann KS (2001) Semaphorin4F interacts with the synapse-associated protein SAP90/PSD-95. J Neurochem 78:482-489.

Semaphorin Nomenclature Committee (1999) Unified nomenclature for the semaphorins/collapsins. Cell 97:551-552.

Shi W, Kumanogoh A, Watanabe C, Uchida J, Wang X, Yasui T, Yukawa K, Ikawa M, Okabe M, Parnes JR, Yoshida K, Kikutani H (2000) The class IV semaphorin CD100 plays nonredundant roles in the immune system: defective $\mathrm{B}$ and $\mathrm{T}$ cell activation in CD100-deficient mice. Immunity 13:633-642.

Shoji W, Yee CS, Kuwada JY (1998) Zebrafish semaphorin Z1a collapses specific growth cones and alters their pathway in vivo. Development 125:1275-1283.

Song H, Ming G, He Z, Lehmann M, McKerracher L, Tessier-Lavigne M, Poo M (1998) Conversion of neuronal growth cone responses from repulsion to attraction by cyclic nucleotides. Science 281:1515-1518.

Summerton J (1999) Morpholino antisense oligomers: the case for an RNase H-independent structural type. Biochim Biophys Acta 1489:141-158.

Taniguchi M, Yuasa S, Fujisawa H, Naruse I, Saga S, Mishina M, Yagi T (1997) Disruption of semaphorin III/D gene causes severe abnormality in peripheral nerve projection. Neuron 19:519-530.

Trevarrow B, Marks DL, Kimmel CB (1990) Organization of hindbrain segments in the zebrafish embryo. Neuron 4:669-679.

Tsuchida T, Ensini M, Morton SB, Baldassare M, Edlund T, Jessell TM, Pfaff SL (1994) Topographic organization of embryonic motor neurons defined by expression of LIM homeobox genes. Cell 79:957-970.

Warren Jr JT, Chandrasekhar A, Kanki JP, Rangarajan R, Furley AJ, Kuwada JY (1999) Molecular cloning and developmental expression of a zebrafish axonal glycoprotein similar to TAG-1. Mech Dev 80:197-201.

Westerfield M (1995) The Zebrafish book. Eugene, OR: University of Oregon

Wong JTW, Yu WTC, O'Connor TP (1997) Transmembrane grasshopper Semaphorin I promotes axon outgrowth in vivo. Development 124:3597-3607.

Wong JTW, Wong STM, O’Connor TP (1999) Ectopic semaphorin-1a functions as an attractive guidance cue for developing peripheral neurons. Nat Neurosci 2:798-803

Xu X, Fisher DA, Zhou L, White FA, Ng S, Snider WD, Luo L (2000) The transmembrane protein semaphorin $6 \mathrm{~A}$ repels embryonic sympathetic axons. J Neurosci 20:2638-2648.

Yee CS, Chandrasekhar A, Halloran MC, Shoji W, Warren JT, Kuwada JY (1999) Molecular cloning, expression, and activity of zebrafish semaphorin Z1a. Brain Res Bull 48:581-593. 